\title{
Tau as a mediator of neurotoxicity associated to cerebral amyloid angiopathy
}

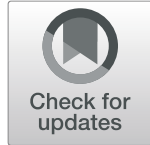

Yingjian You ${ }^{1,2}$, Abigail Perkins ${ }^{1,2}$, Pablo Cisternas ${ }^{1,2}$, Braulio Muñoz ${ }^{1,3}$, Xavier Taylor $^{1,2}$, Yanwen You $^{1,2}$, Holly J. Garringer ${ }^{4,5}$, Adrian L. Oblak ${ }^{1,6}$, Brady K. Atwood ${ }^{1,3,7}$, Ruben Vidal ${ }^{1,4,5}$ and Cristian A. Lasagna-Reeves ${ }^{1,2,8^{*}}$

\begin{abstract}
Cerebral amyloid angiopathy (CAA) is typified by the cerebrovascular deposition of amyloid. Currently, there is no clear understanding of the mechanisms underlying the contribution of CAA to neurodegeneration. Despite the fact that CAA is highly associated with accumulation of $A \beta$, other types of amyloids have been shown to associate with the vasculature. Interestingly, in many cases, vascular amyloidosis is accompanied by significant tau pathology. However, the contribution of tau to neurodegeneration associated to CAA remains to be determined. We used a mouse model of Familial Danish Dementia (FDD), a neurodegenerative disease characterized by the accumulation of Danish amyloid (ADan) in the vasculature, to characterize the contribution of tau to neurodegeneration associated to CAA. We performed histological and biochemical assays to establish tau modifications associated with CAA in conjunction with cell-based and electrophysiological assays to determine the role of tau in the synaptic dysfunction associated with ADan. We demonstrated that ADan aggregates induced hyperphosphorylation and misfolding of tau. Moreover, in a mouse model for CAA, we observed tau oligomers closely associated to astrocytes in the vicinity of vascular amyloid deposits. We finally determined that the absence of tau prevents synaptic dysfunction induced by ADan oligomers. In addition to demonstrating the effect of ADan amyloid on tau misfolding, our results provide compelling evidence of the role of tau in neurodegeneration associated with ADan-CAA and suggest that decreasing tau levels could be a feasible approach for the treatment of CAA.
\end{abstract}

Keywords: Cerebral amyloid angiopathy, Tau oligomers, ADan oligomers, Vascular amyloid, Tau downregulation, Neurodegeneration

\section{Introduction}

Alzheimer disease (AD), the most common form of dementia, is characterized by the extracellular deposition of parenchymal and vascular $\beta$-amyloid $(A \beta)$, intracellular accumulation of tau as neurofibrillary tangles (NFTs), neuronal cell loss, and significant inflammation [15, 39]. Over the past decades, a major focus of research has been the understanding of the connection between parenchymal $\mathrm{A} \beta, \mathrm{NFT}$, and neurodegeneration, while the contribution of vascular pathology to NFT and neurodegeneration remains understudied.

Cerebral amyloid angiopathy (CAA) is typified by the cerebrovascular deposition of amyloid and has a close

\footnotetext{
* Correspondence: clasagna@iu.edu

'Stark Neurosciences Research Institute, Indiana University School of Medicine, Indianapolis, IN 46202, USA

${ }^{2}$ Department of Anatomy \& Cell Biology, Indiana University School of Medicine, Indianapolis, IN 46202, USA

Full list of author information is available at the end of the article
}

molecular relationship with $\mathrm{AD}$, but remains clinically distinct. Vascular amyloid accumulation is identified in an estimated $85-95 \%$ of individuals with $\mathrm{AD}[3,6]$, positioning CAA as one of the strongest vascular contributors to age-related cognitive decline $[9,64]$. The mechanisms responsible for CAA pathogenesis and its downstream effects on the brain are complex and not completely understood [12, 66]. Despite the fact that CAA is highly associated with the accumulation of $A \beta$ [6], other types of amyloids have been shown to associate with the vasculature. It has also been reported that some mutations in the PrP gene may result in the deposition of prion amyloid (APrP) in cerebral vessels (PrP-CAA) [24]. Furthermore, one of the main neuropathological hallmarks of Familial British Dementia (FBD) and Familial Danish Dementia (FDD) is the presence of CAA composed of British-amyloid (ABri) and Danish amyloid (ADan) respectively [22, 61, 63]. These 
observations suggest that CAA is a general term that describes a heterogeneous group of biochemically and genetically diverse central nervous system disorders, characterized by the dynamic accumulation of different amyloid species in the vasculature.

In many cases, vascular amyloidosis is accompanied by significant tau pathology [24, 49, 60]. Although different amyloid peptides are deposited in these conditions, the tau deposits are antigenically and biochemically indistinguishable $[25,27,28,34,35]$. These findings support a unifying pathological mechanism in which vascular accumulation of amyloidogenic peptides triggers a complex pathological cascade leading to tau accumulation and neurodegeneration.

FDD patients are characterized by the presence of CAA composed of the $4 \mathrm{kDa}$ ADan in leptomeninges and vessels of the gray and white matter. Genetic analysis in patients with FDD revealed the presence of a 10-nucleotide duplication insertion in the 3 '-end of the coding region of the BRI2 gene. The mutation in BRI2 causes a frame-shift in the BRI2 sequence, generating a ADan precursor protein of 277 amino acids, of which the $\sim 4 \mathrm{kDa}$ Danish amyloid subunit comprises the last 34 amino acids [22]. Cotton wool-like plaques in the vicinity of blood vessels with amyloid and tau NFTs are also observed in FDD patients [34]. A mouse model for Familial Danish Dementia (Tg-FDD) [59] consistently exhibits CAA primarily in leptomeningeal cerebellar vessels [59] and in large and medium-sized parenchymal and penetrating vessels of the brain. Neuropathologically, a robust glial activation is observed in close vicinity of vascular deposits without the presence of cerebral hemorrhage [59]. Tau immunoreactive deposits in neuropil have also been observed in this model [59], yet the spatial relationship between vascular amyloid deposits and tau in Tg-FDD mice has not been established. Overall these observations make FDD and the Tg-FDD mice a valuable model to study the molecular and cellular mechanisms underlying the role of tau in the neurodegenerative process associated with CAA.

In the present study, we show that ADan induced the phosphorylation and misfolding of tau and subsequent tau-dependent neurotoxicity. Our results suggest that ADan aggregates could have an effect over tau via two different and non-excluding pathways, and how the absence of tau could prevent the synaptic dysfunction induced by CAA-associated amyloid.

\section{Materials and methods}

\section{ADan oligomers preparation}

ADan peptide (EASNCFAIRHFENKFAVETLICFNLFLNSQEKHY) [63] was synthesized by ThermoFisher Scientific using Fmoc-based Solid Phase Peptide Synthesis and purified by HPLC. To prepare ADan oligomers, ADan peptide was resuspended in PBS without calcium and magnesium to a final concentration of $0.5 \mathrm{mg} / \mathrm{mL}$. The ADan solution was then stirred at room temperature (RT) for $48 \mathrm{~h}$. Aliquots were collected at different time points and stored at $-80^{\circ} \mathrm{C}$. To confirm the formation of ADan oligomers, Western Blot (WB) analysis was performed using anti-ADan 1699 antibody (1:1000, developed by $R$. Vidal) that was specific for residues 23-34 (FNLFLNSQEKHY) of the ADan amyloid peptide [59] and the conformational antibody anti-oligomers F11G3 (1:1000, provided by R. Kayed), as previously described [44].

\section{Cell culture, transfection, and oligomers treatment}

Human embryonic kidney cells expressing doxycycline (Dox) inducible full length human tau (2N4R) with the P301L mutation (HEK P301L) ([16] and Additional file 1: Figure S1) were cultured in DMEM (Invitrogen) with 10\% fetal bovine serum (Invitrogen), $2 \mathrm{mM}$ glutamine, $100 \mathrm{U} / \mathrm{mL}$ penicillin, and $100 \mu \mathrm{g} / \mathrm{mL}$ streptomycin. $1 \mu \mathrm{g} / \mathrm{mL}$ Dox was added into the culture media to induce human tau expression $24 \mathrm{~h}$ prior to transfection and ADan oligomer treatment. Human wild-type (WT) $\mathrm{BRI}_{2}$ and $\mathrm{BRI}_{2}$ bearing the Danish mutation were cloned into a pcDNA3.1 vector (Invitrogen). The sequences were confirmed by Sanger sequencing. All plasmids were transfected with Lipofectamine 2000 (Invitrogen) and incubated for $48 \mathrm{~h}$. For ADan oligomer treatment, human Tau expression was induced by $1 \mu \mathrm{g} / \mathrm{mL}$ Dox in HEK P301L cells for $24 \mathrm{~h}$, the cells were treated with $200 \mathrm{nM}$ ADan oligomers, monomers, or PBS for $8 \mathrm{~h}$. All measurements were made in triplicates.

\section{Cell toxicity assay}

HEK P301L cells were plated at 20,000 cells per well in 96-well plates with $1 \mu \mathrm{g} / \mathrm{mL}$ Dox for $24 \mathrm{~h}$. Then the cells were treated with $2.5 \mu \mathrm{M}$ ADan oligomers, monomers, or PBS. After incubation for $4 \mathrm{~h}$ at $37^{\circ} \mathrm{C}$, cell viability was assayed using a 3-(4,5-dimethylthiazol-2-yl)-2,5-diphenyltetrazolium bromide (MTT) cell proliferation assay kit (Promega) according to the manufacturer's specifications. The MTT assay is a colorimetric assay for assessing cell metabolic activity, which reflects the number of viable cells. All measurements were made in six replicates.

\section{Cell lysate preparation and immunoblot analysis}

Cells were washed twice with $0.5 \mathrm{~mL}$ PBS and lysed on ice for $60 \mathrm{~min}$ in $80 \mu \mathrm{LT}$-PER tissue protein extraction reagent (ThermoFisher Scientific) supplemented with Complete protease inhibitors cocktail (Roche). The cell lysates were then centrifuged at $14,800 \mathrm{rpm}$ for $15 \mathrm{~min}$ at $4{ }^{\circ} \mathrm{C}$, the supernatants were analyzed by WB as previously described [44]. Primary antibodies used were anti-tau (tau-5, 1:1500, Abcam), anti-ptau Thr231 
(1:1500, Millipore), PHF1 anti-ptau Ser396/Ser404 (1:1000, provided by Dr. Peter Davies), Anti-BRI 2 (1:100, Santa Cruz Biotech) and Anti-GAPDH (1:10000, Sigma-Aldrich). Tau oligomers levels were measured using the anti-tau oligomer antibody T22 (1:1000, provided by Dr. Rakez Kayed) as previously described [43].

\section{Immunocytochemistry}

HEK P301L cells were plated on the $12 \mathrm{~mm}$ Poly-L-Lysine coated coverslips (Corning BioCoat) in 24-well plates at a density of 62,500 cells per well with $1 \mu \mathrm{g} / \mathrm{mL}$ Dox for $24 \mathrm{~h}$, then cells were transfected with $\mathrm{BRI}_{2}$ bearing the Danish mutation for $48 \mathrm{~h}$. Then, the coverslips were briefly rinsed with warm TBS and fixed with $2 \%$ paraformaldehyde for $10 \mathrm{~min}$ at $\mathrm{RT}$, then permeabilized for $5 \mathrm{~min}$ with $0.1 \%$ Triton $\mathrm{X}-100$. The samples were blocked for $1 \mathrm{~h}$ in $5 \%$ goat serum and incubated overnight (O.N.) at $4{ }^{\circ} \mathrm{C}$ with mouse anti-ptau Thr231 (1:1000, Millipore) and rabbit anti-ADan antibody 1699 (1:500). Cells were then washed in TBS, then incubated with Alexa 488-conjugated goat anti-mouse antibody (1:700, Invitrogen) and Alexa 568-conjugated goat anti-rabbit antibody (1:700, Invitrogen) for $1 \mathrm{~h}$ at RT, then washed with TBS and mounted with Vectashield mounting medium with DAPI (Vector Laboratories). Samples were examined using a Leica DMi 8 epifluorescence microscope coupled with the LAS $\mathrm{X}$ program (Leica). For orthogonal images of reconstructed three-dimensional views a Nikon A1-R Laser Scanning Confocal Microscope coupled with the NIS Element Advanced Research software was utilized.

\section{Transgenic mouse model}

Tg-FDD, wild type C57/BL6J (WT) (JAX stock \#000664) and Tau knock out $\left(\mathrm{Tau}^{-/-}\right.$) (JAX stock \#007251) male and female mice were used for our experiments, including cellular, biochemical, and immunohistochemistry (IHC) analyses. The Tg-FDD mouse model [59] expresses a FDD-associated human mutant $\mathrm{BRI}_{2}$ transgene. Mice were housed at the Indiana University School of Medicine (IUSM) animal care facility and were maintained according to USDA standards (12-h light/dark cycle, food and water ad libitum), in accordance with the Guide for the Care and Use of Laboratory Animals (National Institutes of Health, Bethesda, MD). Animals were anesthetized and euthanized according to IUSM Institutional Animal Care and Use Committee-approved procedures. Tissue was collected from 3 and 18 months old animals (5 mice per genotype). Mice were deeply anesthetized and perfused transcardially with PBS prior to decapitation. After sacrifice, brains were removed and stored at $-80^{\circ} \mathrm{C}$ or formalin fixed as previously described [59].

\section{Mouse brain samples preparation and immunoblot analysis}

Tg-FDD and WT (5 mice per genotype) brains were homogenized at a 1:10 (w/vol) ratio of brain and T-PER tissue protein extraction reagent with complete protease inhibitor cocktail (Roche). Samples were then centrifuged at $13,200 \mathrm{rpm}$ for $15 \mathrm{~min}$ at $4{ }^{\circ} \mathrm{C}$. The supernatants were aliquoted, snap-frozen, and stored at $-80{ }^{\circ} \mathrm{C}$ until analyzed. The T-PER insoluble pellets were resuspended in $88 \%$ formic acid (FA) at one fourth volume of their brain homogenates, then incubated for $1 \mathrm{~h}$ at RT. Samples were then diluted with distilled water to obtain the same volume used for brain homogenates. Samples were then lyophilized for $24 \mathrm{~h}$. Freeze-dried samples were reconstituted in PBS using the same volume as brain homogenates, then sonicated for $30 \mathrm{~s}$. Finally, samples were mixed with sample loading buffer, run on a NuPAGE 4-12\% Bis-Tris protein gel (Invitrogen), and analyzed by WB. Primary antibodies used were anti-BRI (1:100, Santa Cruz Biotech), Tau-5 (1:1500, Abcam), PHF1 (anti-ptau Ser396/Ser404) (1:1000, gift from Peter Davies), anti-ptau Thr231 (1:1500, Abcam), MC1 (1:100, gift from Peter Davies), and anti-Vinculin (1:10000, Invitrogen). Secondary antibodies used: goat anti-mouse HRP IgG (1:1500, Invitrogen) and goat anti-rabbit HRP IgG (1:1500, Invitrogen). WB quantification results are expressed as the ratio of phospho-tau to total tau levels. Then this value was normalized by the loading control. In all cases, we considered the control group as the $100 \%$. For the FA treated samples, equal amount of proteins were loaded, previously determined by Bradford assay (ThermoFisher Scientific) according to manufacturer's specification.

\section{Brain sections immunofluorescence (IF)}

Paraffin sections were deparaffinized in xylene and rehydrated in ethanol $(\mathrm{EtOH})$ and washed with deionized water. Then the sections were heated with a microwave oven in low $\mathrm{pH}$ antigen retrieval solution (eBioscience) twice for $4 \mathrm{~min}$ each. After washing in TBS twice for 5 min each, the sections were blocked in 5\% normal goat serum for $1 \mathrm{~h}$ at RT, sections were incubated O.N. at $4{ }^{\circ} \mathrm{C}$ with the following antibodies: anti-ADan 1699 (1:500), T22 (1:100, gift from Dr. Rakez Kayed), TOMA (1:750, gift from Dr. Rakez Kayed), MC1 (1:750, gift from Dr. Peter Davies), anti-GFAP antibody (1:200, Sigma-Aldrich), anti-Iba1 (1:250, Millipore), and NeuN (1:100, Abcam). For amyloid detection, sections were first stained with $1 \%$ Thioflavin S (Thio-S) in TBS for 8 min before the primary antibody incubation, then washed in EtOH and deionized water. The next day, the sections were washed in TBS and incubated with secondary antibodies Alexa 488-conjugated goat anti-mouse antibody (1:500, Invitrogen) and Alexa 568-conjugated goat anti-rabbit 
antibody (1:500, Invitrogen) for $1 \mathrm{~h}$ at RT. Finally, sections were washed in TBS and mounted with Vectashield mounting medium with DAPI (Vector Laboratories). For colocalization analysis we utilized the Coloc 2 plugin from Fiji that implements and performs the pixel intensity correlation over space methods of Pearson [55]. For every single staining, as a negative control, primary antibodies were omitted to determine background and autofluorescence (not shown). WT and Tg-FDD cerebral cortex was examined using a Leica DMi 8 epifluorescence microscope coupled with the LAS X program (Leica).

\section{Quantitative PCR}

Mouse brains total RNA were isolated with RNeasy Plus Universal Mini kit (Qiagen). cDNA was prepared from $1 \mu \mathrm{g}$ total RNA with High-Capacity cDNA reverse transcription kit (Life Technologies). All qPCRs were performed on QuantStudio 6 Flex Real-Time PCR system (Life Technologies). The mouse Mapt relative gene expression was evaluated with delta $\mathrm{Ct}$ method using Taqman probe sets (Mapt: Mm00521988_m1, GAPDH: 4351309, Life Technologies) and TaqMan Universal PCR Master Mix.

\section{Brain slice preparation}

Immediately following euthanasia via decapitation under deep isoflurane anesthesia, the brain was quickly excised and placed in an ice-cold tissue cutting solution containing (in $\mathrm{mM}$ ): 194 sucrose, $30 \mathrm{NaCl}, 4.5 \mathrm{KCl}, 1$ $\mathrm{MgCl}_{2}, 26 \mathrm{NaHCO}_{3}, 1.2 \mathrm{NaH}_{2} \mathrm{PO}_{4}, 10$ Glucose saturated with a mixture of $95 \% \mathrm{O} 2$ and $5 \% \mathrm{CO} 2$, and sliced to a thickness of $280 \mu \mathrm{m}$ on a vibratome (Leica VT1200S, Germany). Slices were transferred to an artificial cerebrospinal fluid (aCSF) solution containing (in $\mathrm{mM}$ ): $124 \mathrm{NaCl}$, $4.5 \mathrm{KCl}, 1 \mathrm{MgCl}_{2}, 26 \mathrm{NaHCO}_{3}, 1.2 \mathrm{NaH}_{2} \mathrm{PO}_{4}, 10$ Glucose, $2 \mathrm{CaCl}_{2}$ (310-320 mOsm) saturated with 95\% O2/5\% $\mathrm{CO} 2$ at $30^{\circ} \mathrm{C}$ for $1 \mathrm{~h}$ before being moved to RT. When ready for recording, in control conditions, slices were transferred to a recording chamber continuously perfused with aCSF solution saturated with $95 \% \mathrm{O} 2 / 5 \% \mathrm{CO} 2$. In experiments using the ADan oligomer, the slices were first transferred to an incubation chamber containing aCSF containing $400 \mathrm{nM}$ ADan oligomer saturated with 95\% $\mathrm{O} 2 / 5 \% \mathrm{CO} 2$ at RT for at least $1 \mathrm{~h}$ before being transferred to the recording chamber.

\section{Primary cerebellar granule neurons culture and immunofluorescence}

Cerebellums were obtained from 8 to 10 days old mouse pups from WT C57/BL6J (JAX stock \#000664) and Tau knock out (JAX stock \#007251) mice. Their brains were dissected, the cerebellum separated, cleaned thoroughly from meninges, and incubated with $0.25 \%$ trypsin EDTA and $25 \mathrm{mg} / \mathrm{mL}$ DNase. Then they were disaggregated by passing them through a $22^{1 / 2} \mathrm{G}$ syringe needle previously coated with $100 \mathrm{mg} / \mathrm{mL}$ BSA in ultrapure cell culture grade water. The suspension was centrifuged for $5 \mathrm{~min}$ at $1250 \mathrm{rpm}$, and then cells were resuspended in 8 $\mathrm{mg} / \mathrm{mL}$ BSA. A second centrifugation was followed by a resuspension in $2 \mathrm{mg} / \mathrm{mL}$ BSA. Finally, cells were resuspended a third time in primary granule neuron media (1X Neurobasal medium, Invitrogen) and counted. They were seeded in 24-well plates that contained coverslips previously treated with $0.01 \%$ poly-L-lysine. Seeding number was 50,000 cells/well. After 14 days in vitro (DIV), cells were fixed for $15 \mathrm{~min}$ at $37^{\circ} \mathrm{C}$ in a solution of $4 \%$ paraformaldehyde/sucrose in TBS. Cells were washed with TBS, permeabilized with $0.25 \%$ Triton $\mathrm{X}-100$ in TBS, and blocked with 10\% BSA in TBS. Primary antibodies anti-Synapsin 1 (1:100, Abcam) and anti-PSD95 (1:100, Abcam) were incubated O.N. at $4{ }^{\circ} \mathrm{C}$. The next day cells were washed in TBS, permeabilized in $0.25 \%$ Triton $\mathrm{X}-100$, and incubated with secondary antibodies Alexa Fluor-488 anti-mouse (1:100, Invitrogen) and Alexa Fluor-568 anti-rabbit (1:100, Invitrogen) for $1 \mathrm{~h}$ at RT. Finally, cells were washed in TBS for $3 \mathrm{~min}$, mounted with Vectashield mounting medium with DAPI, and visualized using a Leica DMi 8 epifluorescence microscope coupled with the LAS X program (Leica). Clusters of Synapsin 1 and PSD95 were quantified as previously described [14].

\section{Field potential recordings}

Field excitatory postsynaptic potential (fEPSP) recordings from the stratum radiatum of hippocampal area CA1 were carried out at $29-32{ }^{\circ} \mathrm{C}$ and aCSF was continuously perfused at a rate of $1-2 \mathrm{ml} /$ minute using a Multiclamp 700B amplifier (Axon Instruments, Union City, CA) signals were amplified (gain 100) and filtered $(1 \mathrm{kHz})$, then digitized $(10 \mathrm{kHz})$. Slices were visualized on an Olympus BX51WI microscope (Olympus Corporation of America). Picrotoxin $(50 \mu \mathrm{M})$ was added to the aCSF for recordings to isolate excitatory potentials. Micropipettes were prepared from filament-containing borosilicate micropipettes (World Precision Instruments) using a P-1000 micropipette puller (Sutter Instruments, Novato, CA), having a $2.0-3.5 \mathrm{M} \Omega$ resistance. The glass micropipettes were filled with $1 \mathrm{M} \mathrm{NaCl}$ and placed into the stratum radiatum of hippocampal area CA1. A concentric bipolar stimulating electrode (FHC, Bowdoin, ME) was placed into stratum radiatum in area CA1 $500 \mu \mathrm{m}$ from the recording site. fEPSPs were generated by a DS3 Isolated Current Stimulator (Digitimer, Ft. Lauderdale, FL) every $20 \mathrm{~s}$ and stimulus intensity was adjusted to produce stable fEPSP responses prior to the initiation of experimental recording. A $10 \mathrm{~min}$ baseline was recoded before delivery of four high frequency stimulations (HFS; $100 \mathrm{~Hz}$, 
$1 \mathrm{~s}$ duration, $10 \mathrm{~s}$ inter-stimulus-interval). Data were acquired using Clampex 10.3 (Molecular Devices, Sunnyvale, CA). The representative traces were obtained from the average baseline fEPSP (1-10 min) and average post-HFS fEPSP of the final $10 \mathrm{~min}$ of recording. Exclusion of individual data points was determined using an outlier calculator included in the Prism 7 software package. Recordings were made $2-7 \mathrm{~h}$ after euthanasia. The analysis of fEPSP slopes were used to determine the effects of ADan oligomer. The experimenter was not blinded to treatments administered to the slices.

\section{Statistical analyses}

Experimental analysis and data collection were performed in a blinded fashion, if not stated otherwise. $P$ values were determined using the appropriate statistical method via GraphPad Prism, as described throughout the manuscript. Statistical comparisons were made using two-tailed unpaired Student's t-test with Welch's correction, Mann-Whitney test or one-Way ANOVA with Tukey's correction. Figures $1 \mathrm{~b}, 2 \mathrm{~d}, 3 \mathrm{~b}-\mathrm{d}$, and $8 \mathrm{C}$ use unpaired Student's t-test follow by Welch's correction. Figure 7b-d use Mann-Whitney test and Fig. 2c use one-Way ANOVA followed by Tukey's correction. Data are presented as mean \pm SD if not stated otherwise. ${ }^{*}$, **, ${ }^{* * * *}$, and $* * * *$ denote $P<0.05, \quad P<0.01, \quad P<0.001$, and $P<0.0001$ respectively. All details of experiments can be found in the Results or the Figure Legends.

\section{Results}

\section{The ADan peptide leads to hyperphosphorylation of tau}

FDD patients are not only characterized by the vascular accumulation of ADan amyloid, but also by the accumulation of hyperphosphorylated tau. Therefore, we decided to determine in a cellular model if ADan promotes tau hyperphosphorylation. To do so, we transfected $\mathrm{BRI}_{2}$ bearing the Danish mutation in HEK cells, lacking endogenous tau, that conditionally express human tau with the P301L mutation after the addition of Dox [16]. As a control, we transfected $\mathrm{WT} \mathrm{BRI}_{2}$. Danish mutant $\mathrm{BRI}_{2}$ overexpression led to an increase in the levels of phosphorylated tau at Ser396/Ser404 and Thr231 (Fig. 1a-b). To determine if the effect of ADan aggregates over tau phosphorylation and aggregation is mediated by a direct interaction between ADan peptides and tau or by an indirect mechanism, we performed double-immunostaining using an anti-ADan antibody and an anti-phospho tau antibody (Thr231). We observed colocalization of ADan immunoreactivity with phospho-tau Thr231 in a number of cases, but this was not observed in all cases (Fig. 1c). Overall, these results suggested that the expression of $\mathrm{BRI}_{2}$ bearing the Danish mutation could induce the aggregation and phosphorylation of tau, a process that, in cell culture, could be mediated by a direct event or by an indirect mechanism.

\section{ADan oligomers promote tau phosphorylation and toxicity by a mechanism that is tau dependent}

Since $\mathrm{BRI}_{2}$ is a transmembrane protein and the Danish mutation induced the secretion of the ADan peptide to the extracellular space [22] (Additional file 1: Figure S2), we evaluated the effect of ADan monomers and oligomers over tau phosphorylation and cellular toxicity. To test this, we prepared ADan recombinant oligomers as we previously described [44]. Figure 2 a shows the formation of ADan oligomers immunoreactive with the conformational anti-oligomer F11G3 antibody after $48 \mathrm{~h}$ of stirring. Incubation of ADan oligomers or monomers with HEK cells that conditionally express mutant tau for $8 \mathrm{~h}$ showed that when cells are exposed to ADan oligomers, tau becomes hyperphosphorylated (Fig. 2b-c). These ADan oligomers and even monomers, in a lower degree, are able to get internalized into the cells (Additional file 1: Figure S3). Moreover, cells treated with oligomers for $4 \mathrm{~h}$ showed a significant cellular toxicity as measured by the MTT cell proliferation assay (Fig. 2d). Surprisingly, ADan oligomer toxicity was only observed when cells were induced to express human tau after the addition of Dox, but not when cells did not express it (Fig. 2d). Overall, these results suggest that ADan oligomers could induce tau hyperphosphorylation and subsequent tau-dependent toxicity.

\section{Accumulation of endogenous murine tau in a mouse model for familial Danish dementia}

We tested whether ADan aggregates affect endogenous murine tau phosphorylation in vivo in the Tg-FDD model, which is characterized by ADan amyloid deposits in the vasculature [59] (Additional file 1: Figure S4). WB analysis of soluble brain fractions showed a significant increase in phosphorylated tau at Ser396/Ser404 and Thr231 in 18 months old Tg-FDD mice compared to WT controls of the same ages (Fig. 3a-c). No changes in the levels of phosphorylated tau at Ser202/Thr205, Ser214, Ser262 and Ser356 were observed (data not shown). When we performed WB analysis using the MC1 antibody that recognizes early stages of tau misfolding, we observed a significant increase in MC1-positive tau (Fig. 3a and d), suggesting that the accumulation of vascular amyloid in the Tg-FDD model promotes murine tau misfolding. Quantification of murine tau mRNA levels did not show any differences between Tg-FDD and WT mice (Fig. 3e), demonstrating that the effect of ADan amyloid in the Tg-FDD model over tau is at the protein level. We then performed biochemical characterizations of the insoluble brain 
fractions from WT and Tg-FDD mice. WB analysis of these fractions demonstrated the presence of insoluble ADan in the Tg-FDD mice (Fig. 3f), but not tau (Fig. 3f) or phospho-tau (data not shown), suggesting that in the Tg-FDD model endogenous murine tau does not accumulate into insoluble aggregates. Interestingly, whenever we performed WB analysis of soluble brain fractions from 3 months old Tg-FDD mice, an age when no vascular amyloid is observed [59], no changes in the level of phosphorylated tau were observed (Additional file 1: Figure S5). Overall, these results suggest that vascular amyloid accumulation possibly induces endogenous tau phosphorylation and misfolding.

To confirm the amyloidogenic nature of ADan deposits in the vasculature of the Tg-FDD model, we double stained brain sections of 18 months old mice with the ADan antibody and Thio-S. We observed that ADan deposition in the cerebral vessels was mainly

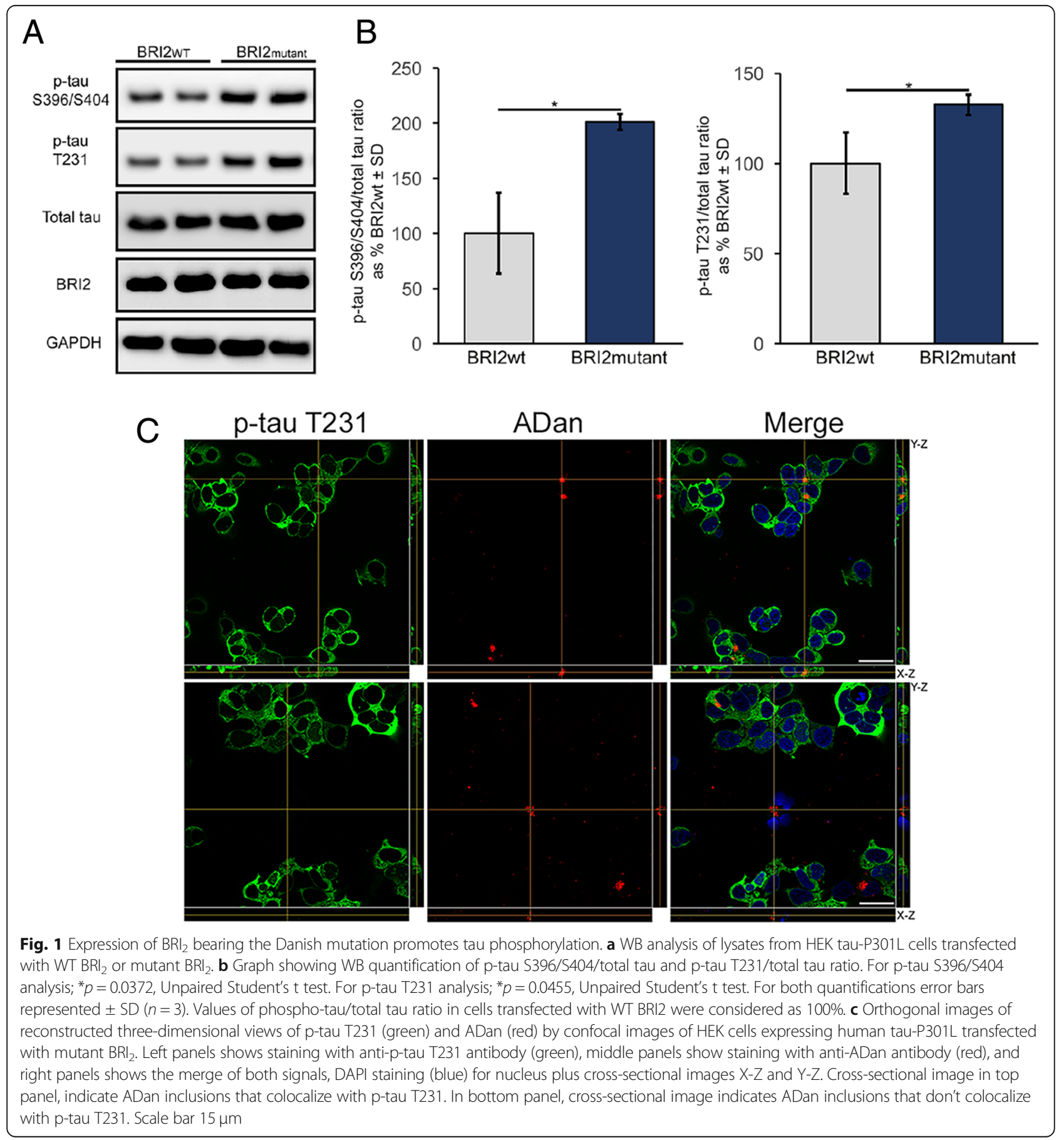




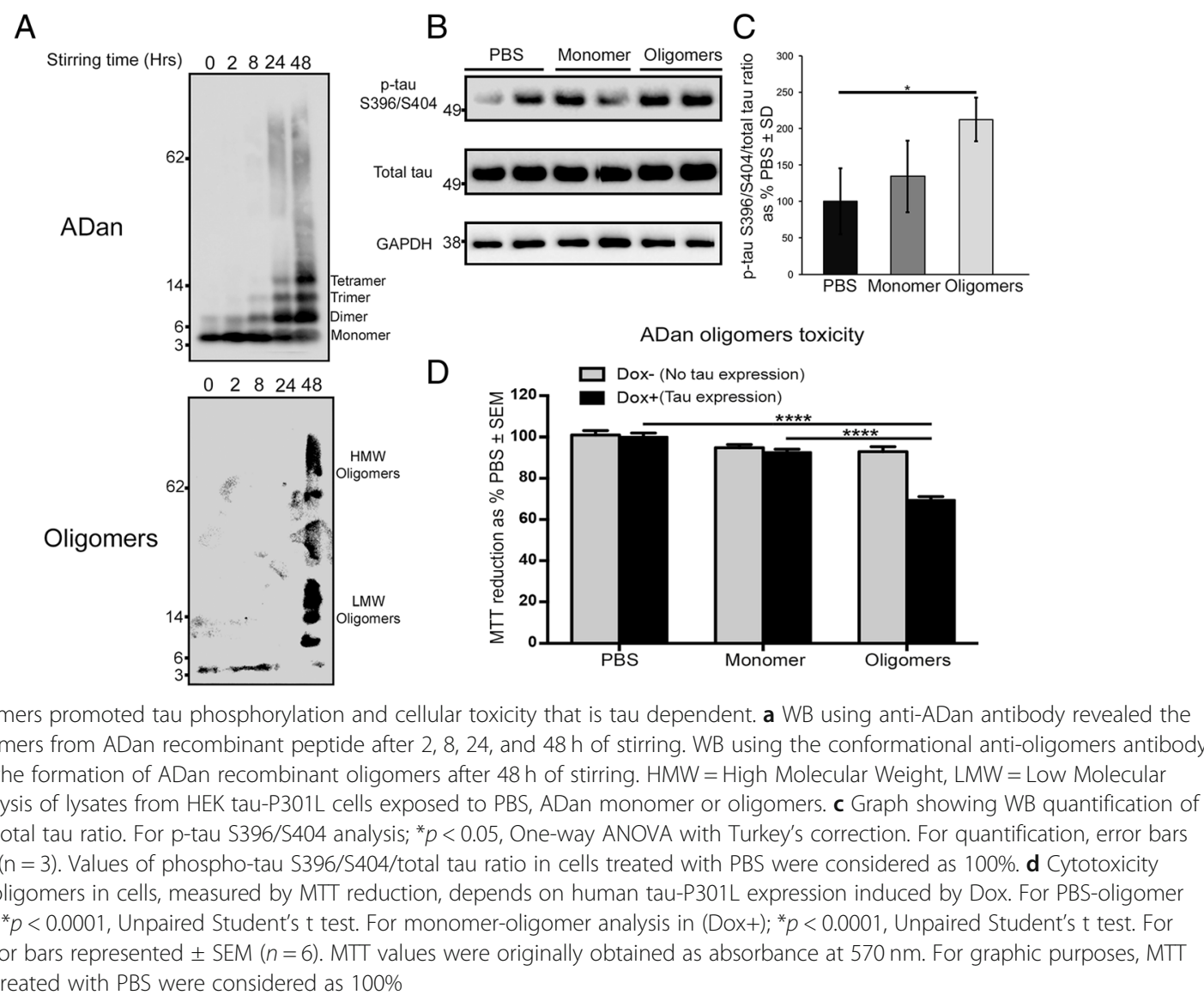

Thio-S-positive (Fig. 4a-c). Interestingly, small ADan depositions negative for Thio-S were also observed (Fig. 4a-c). To determine the presence of ADan soluble aggregates, such as oligomers, we performed double immunofluorescence in brain sections using the ADan antibody and the conformation specific monoclonal anti-oligomer F11G3 antibody (Fig. 4d-f) [31, 44]. Substantial intracellular co-localization between both antibody signals was observed (Fig. 4f).

We performed double immunofluorescence in adjacent sections using anti-ADan and MC1 or TOMA antibodies to assess the spatial relationship between vascular ADan deposits and tau. Both MC1 and TOMA antibodies recognized early stages of tau aggregation such as oligomers $[11,37]$. Double staining of anti-ADan and TOMA on Tg-FDD sections showed the accumulation of tau oligomers in the vicinity of vessels enriched with amyloid deposits in the cortex (Fig. 5a, top and bottom panel). Double staining of anti-ADan and MC1 confirmed the presence of misfolded tau surrounding ADan-positive vessels (Fig. 5b, top panel). Interestingly, double staining of anti-ADan and MC1 also revealed intracellular association between ADan and MC1-positive tau in the cerebral cortex (Fig. 5b, bottom panel). Overall these results demonstrated the presence of two types of pathological accumulation of tau in this CAA model. One where misfolded tau accumulates in the vicinity of vessels enriched with ADan deposits, and a second one where misfolded tau co-localized with ADan intracellular signal in areas of the cerebral cortex, where no major vascular amyloid deposits are observed. Tau oligomers were observed in other brain regions (Additional file 1: Figure S6) that have been previous associated with the accumulation of vascular amyloid in this mouse model [59].

\section{Tau oligomeric deposits in the vicinity of vascular amyloid are closely associated with astrocytic profile} Innate immunity is activated both in cerebrovascular disease [38] and in AD. In the context of our CAA model, we observed severe astro and microgliosis, as evidenced by robust GFAP and Iba1 staining in areas affected by ADan amyloid vascular deposits (Additional file 1: Figure S7). Based on this observation, we decided to determine which cell type showed tau oligomers associated with vascular amyloid. We performed triple immunofluorescence in Tg-FDD brain sections for Thio-S (amyloid), T22 (tau oligomers), and GFAP or Iba1 or NeuN for astrocytes, microglia, or neurons, respectively. Fluorescent 

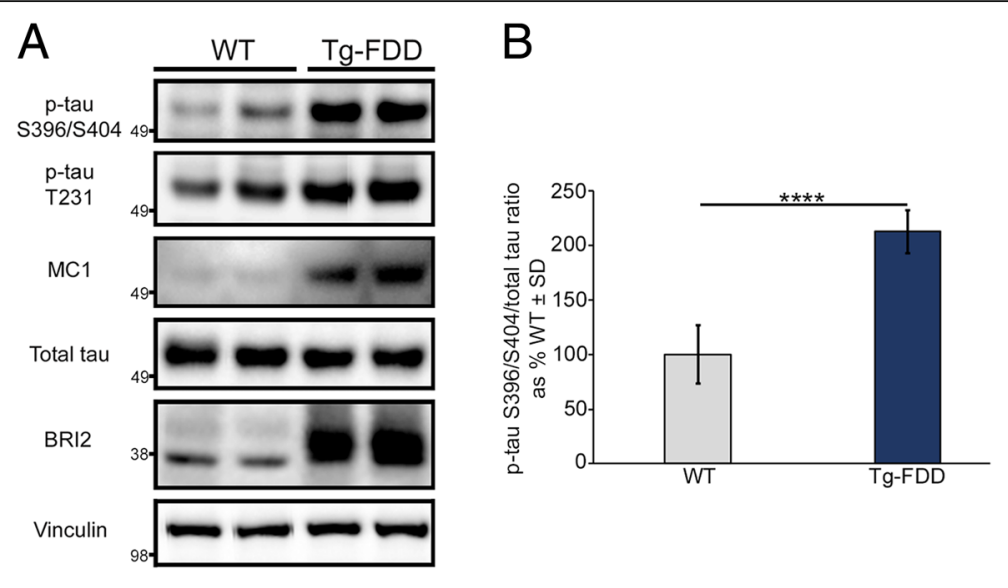

C
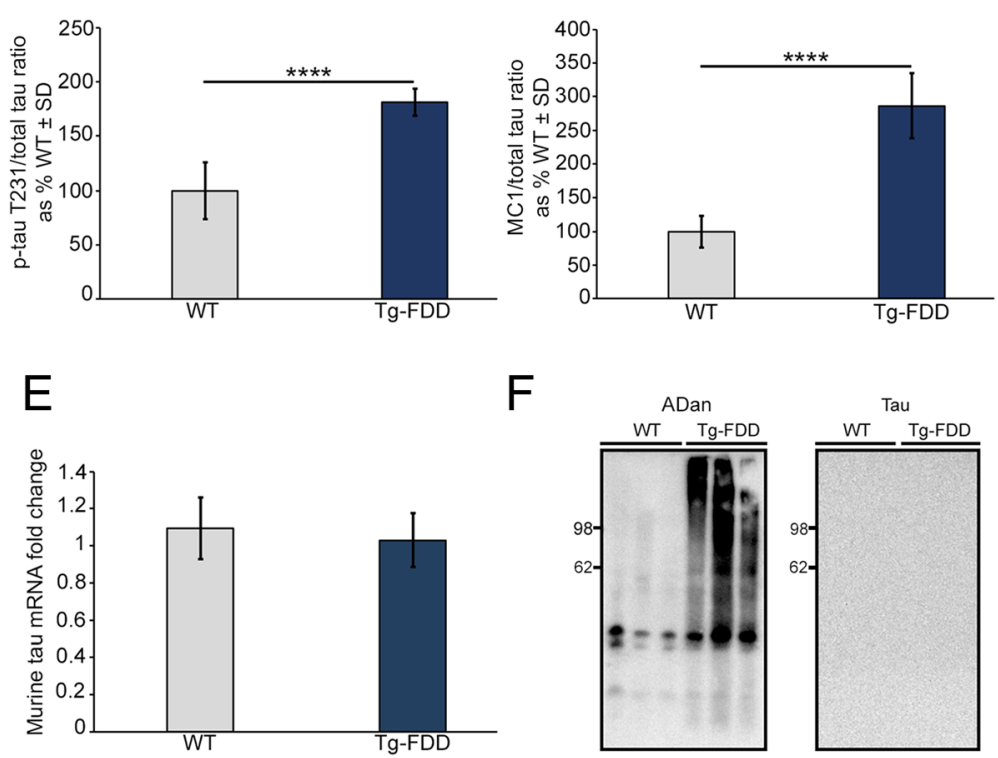

$\mathrm{F}$

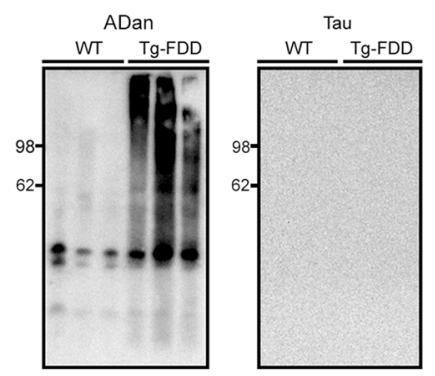

Fig. 3 Tau hyperphosphorylation and misfolding in Tg-FDD mice. a WB analysis of brain lysate from WT and Tg-FDD 18 months old mice. WB using anti-BRI2 antibody was performed to confirm mice genotypes and Vinculin was used as a loading control. b Graph showing WB quantification of p-tau S396/S404/total tau ratio. ${ }^{* * *} p<0.0001$, Unpaired Student's t test. c Graph showing WB quantification of p-tau T231/total tau ratio. ${ }^{* * *} p<0.0001$, Unpaired Student's $t$ test. $\mathbf{d}$ Graph showing WB quantification of MC1 tau/total tau ratio. ${ }^{* * *} p<0.0001$, Unpaired Student's $t$ test. For all three quantifications (b-d) error bars represented \pm SD $(n=5)$. Values from WT mice were considered as $100 \%$. (e) Endogenous murine tau mRNA levels measured by qRT-PCR did not change in Tg-FDD mice in comparison with WT mice $(n=5)$. $\mathbf{f}$ WB analysis of brain insoluble fractions from WT and Tg-FDD demonstrated the presence of ADan insoluble aggregates in Tg-FDD detected using the anti-ADan antibody (left blot). No tau (using tau-5 antibody) was detected in the insoluble fraction neither from WT nor Tg-FDD mice (right blot)

microscopy suggests that tau oligomers are closely associated with GFAP-positive astrocytes (Fig. 6a-e). Co-localization analysis between T22 and GFAP signal suggest that these oligomers are located in the cytoplasm and astrocytic processes (Fig. 6e). Triple staining with Thio-S, T22, and Iba1 showed that tau oligomers were not associated with Iba1-positive microglia (Fig. 6f-j). Interestingly, triple staining revealed that tau oligomers are associated with neurons in areas throughout the cortex where no Thio-S-positive vascular structures were located (Fig. 6k-o). Substantial co-localization between
T22 and NeuN antibody signals was observed (Fig. $60)$.

Tau is required for ADan-induced impairment of the structure and function of neuronal synapses

It is widely accepted that the adverse effects of $A \beta$ on neuronal degeneration and cognitive dysfunction appear to depend largely on soluble tau [29]. For instance, it has been reported that the reduction of tau expression prevents $A \beta$-induced neurodegeneration in cell culture [51, 65]. Moreover, in vivo studies have shown how 

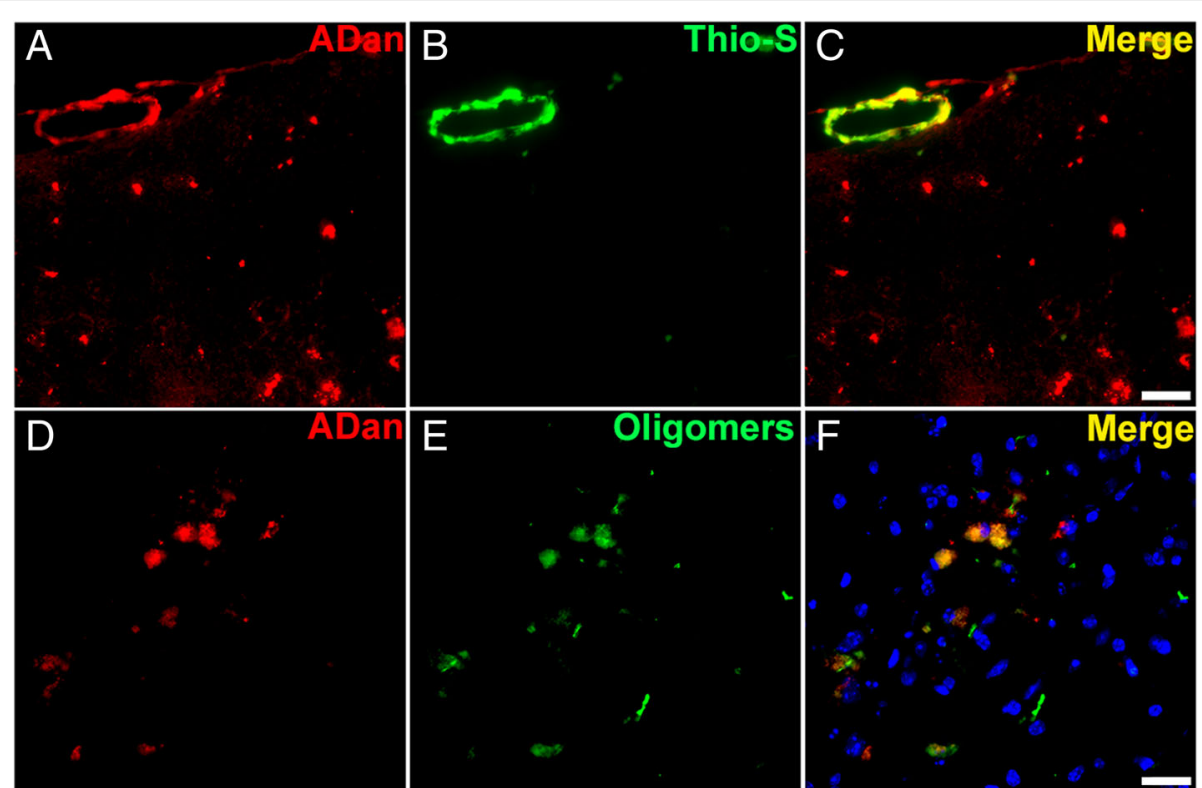

Fig. 4 Amyloid characterization in Tg-FDD mice. a-c Double immunofluorescence using anti-ADan antibody (a, red) and Thio-S (b, green) in brain sections of Tg-FDD mice confirm the presence of Thio-S-positive ADan amyloid in the vasculature (c, Merge). e-f Double immunofluorescence using anti-ADan antibody (e, red) and the anti-oligomer antibody F11G3 (f, green) in brain sections of Tg-FDD mice confirm the presence of ADan oligomers in the cortex (f, Merge). Both are representative images of the cerebral cortex of 18 months old Tg-FD mice. Scale bar $20 \mu m$

genetic ablation of endogenous murine tau in a hAßPP mouse model prevents behavioral deficits without altering the amount of $A \beta$ plaques in the parenchyma [54]. Therefore, considering these previous studies, in addition to the fact that a decrease in the levels of synaptic markers in Tg-FDD mice has been reported [23], we aimed to investigate if the neuronal damage triggered by ADan, a highly vasculotropic amyloid, is also dependent on tau.

To investigate if ADan aggregates induce impairment of the synaptic structure via tau, we performed IF for the pre- and post-synaptic markers Synapsin-1 and PSD95 respectively, and assessed their localization at synapses in cultured primary cerebellar granule neurons from WT mice and mice with a genetic knock-out of Mapt gene $\left(\mathrm{Tau}^{-/-}\right)$in the presence or absence of ADan oligomers (Fig. 7a). Our results show a decrease in the total number of clusters or puncta marked for Synapsin-1 and PSD95 in WT neurons incubated with $500 \mathrm{nM}$ of ADan oligomers in comparison with untreated WT control groups. Remarkably, ADan oligomers did not have

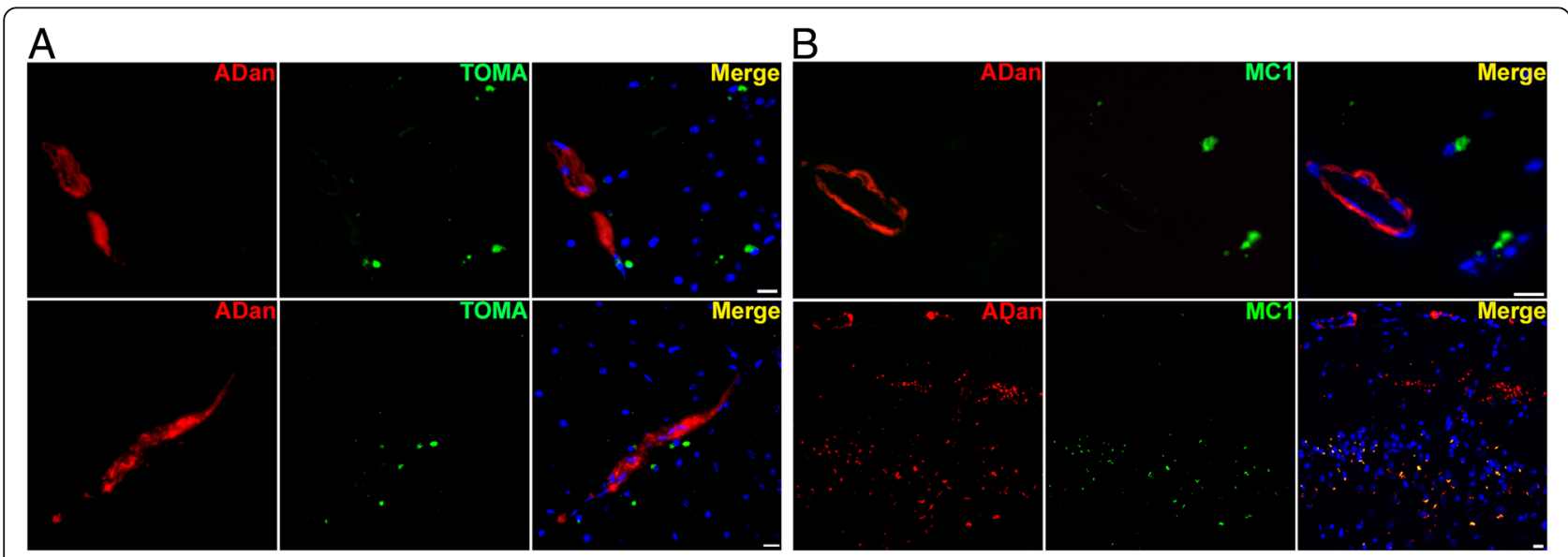

Fig. 5 Spatial relationship between tau oligomers and ADan deposits in Tg-FDD mice. a Accumulation of tau oligomers detected by TOMA (green) in the vicinity of ADan vascular amyloid detected by anti-ADan antibody (red). b Top panel shows accumulation of MC1-positive tau (green) around ADan vascular amyloid (red). Bottom panel shows intracellular localization of ADan deposits (red) and MC1 tau (green) immunoreactivity. All figures were obtained from 18 months old Tg-FDD mice cerebral cortex. Scale bar $15 \mu \mathrm{m}$ 


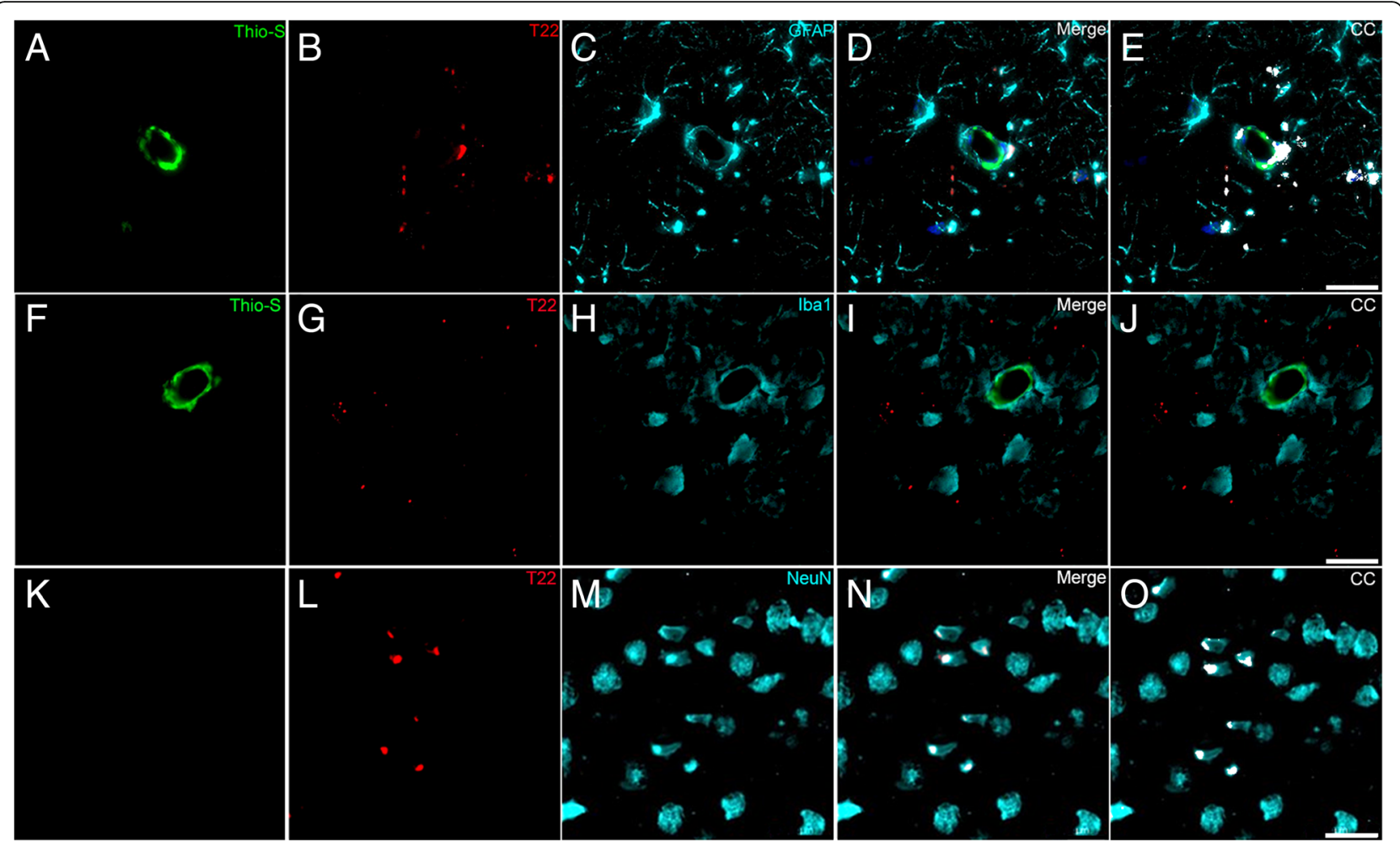

Fig. 6 Tau oligomers cell specificity in Tg-FDD mice. a-e Fluorescent microscopic images of Tg-FDD brain section triple immunostaining for amyloid (Thio-S, green), Tau oligomers (T22, red), and astrocytes (GFAP, cyan). Tau oligomers immunoreactivity showed close association with astrocytes and astrocytic processes (Merge). Colocalization analysis (CC) was performed to determine pixel intensity correlation between T22 and GFAP signals. White pixels indicate colocalization between T22 and GFAP signal (e, white pixels). $\mathbf{f}-\mathbf{j}$ Triple immunostaining for amyloid (Thio-S, green), Tau oligomers (T22, red), and microglia (Iba1, cyan). Tau oligomers are not associated to microglia surrounding vascular amyloid (Merge). Colocalization analysis confirmed the lack of correlation between T22 and Iba1 signal (j). k-o Triple immunostaining for amyloid (Thio-S, green), Tau oligomers (T22, red), and neurons (NeuN, cyan). Tau oligomers were found associated to neurons in areas where vascular amyloid was not detected. White pixels indicate colocalization between T22 and NeuN signal (o, white pixels). All figures were obtained from 18 months old Tg-FDD mice cerebral cortex. Scale bar $25 \mu \mathrm{m}$

any effect on the number of clusters marked either for Synapsin-1 or PSD95 on Tau ${ }^{-/-}$neurons (Fig. 7b-c). ADan oligomers not only affected the number of Synapsin-1 and PSD95 clusters in WT neurons, but also has a detrimental effect on the colocalization between these pre- and post-synaptic markers. On the other hand, no effect on the synaptic colocalization between Synapsin-1 and PSD-95 was observed in $\mathrm{Tau}^{-1-}$ neurons after the addition of ADan oligomers (Fig. 7d). To correlate these results with a functional analysis, we performed hippocampal long-term potentiation (LTP) experiments in hippocampal area CA1 in WT and $\mathrm{Tau}^{-1-}$ mouse-derived brain slice preparations. We monitored fEPSPs evoked by extracellular stimulation of the Schaffer collateral pathway and induced LTP using high-frequency stimulation (four stimuli of $100 \mathrm{~Hz}$ for $1 \mathrm{~s}$ with a $10 \mathrm{~s}$ inter-stimulus interval). In WT slices pretreated with $400 \mathrm{nM}$ ADan oligomers for $2 \mathrm{~h}$, LTP was almost completely blocked (Fig. 8a and c). This was a specific effect of ADan oligomers, because control slices showed LTP (Fig. 8a and c).
These results demonstrate that, in WT mice, acute application of ADan impairs one or more of the cellular mechanisms necessary for LTP. To confirm a possible functional interaction between ADan and tau, we tested the effect of ADan oligomers on LTP in $\mathrm{Tau}^{-1-}$ mice. Slices incubated in the control solution showed normal levels of LTP and, remarkably, slices preincubated in ADan oligomers showed LTP levels of similar magnitude (Fig. 8b-c).

Overall, these results indicate that the absence of tau could prevent the synaptic dysfunction induced by a CAA-associated amyloid such as ADan.

\section{Discussion}

The data reported here shows that ADan amyloid peptide, the amyloid responsible for wide spread CAA in FDD patients, induces the phosphorylation and misfolding of tau in vitro and in vivo. We also demonstrated that ADan oligomers exert cellular toxicity and 

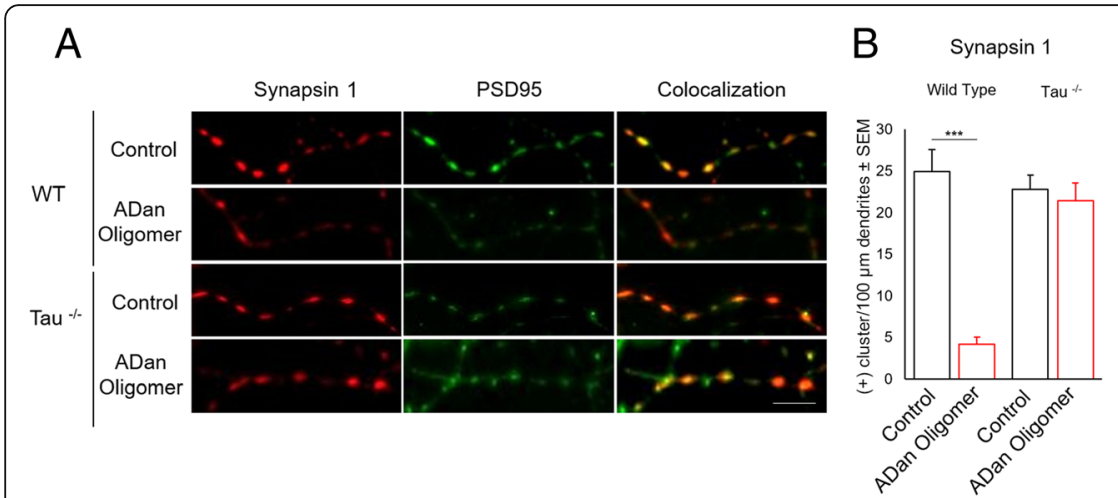
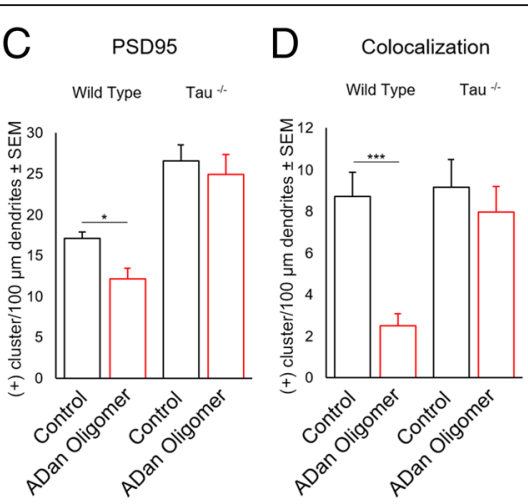

Fig. 7 ADan oligomers do not alter the number and localization of synaptic proteins in $\mathrm{Tau}^{-1-}$ mice derived cerebellar granule neurons. a Representative immunofluorescence photographs for clusters of the synaptic proteins Synapsin-1 (red), PSD95 (green), and their colocalization (yellow) in cerebellar granule neuronal dendrites. Four experimental groups were analyzed: WT and Tau ${ }^{-1-}$ neurons in the presence or absence of ADan oligomers (+ADan, b-d) Graphs showing the quantification of positive ((+)) clusters for each marker and their colocalization per $100 \mu \mathrm{m}$ of dendrite. The number of cells analyzed was 15 per each culture, from 3 independent cultures. Results are shown as the mean $\pm \operatorname{SEM}$ of $n=3$. Asterisks indicate significant differences, where ${ }^{*} p<0.05$ and ${ }^{* *} p<0.001$ by Mann-Whitney test. Scale bar $=10 \mu \mathrm{m}$

hippocampal LTP impairment in brain slices in a tau dependent manner.

Previous studies reported the existence of several neurodegenerative diseases characterized by vascular amyloid deposition known as CAA [52, 58]. Among CAAs, A $\beta$-CAA is the most common and is frequently present in $\mathrm{AD}$ [42]. Other examples include the accumulation of vascular ADan amyloid or ABri amyloid in patients with Familial Danish Dementia and Familial British Dementia, respectively [61, 63]. Vascular accumulation of amyloidogenic forms of Cystatin C, Gelsolin, Transthyretin, and prion protein are pathological hallmarks of Hereditary cystatin $\mathrm{C}$ amyloid angiopathy, Familial amyloidosis Finnish type, Familial transthyretin amyloidosis (FTA)-leptomeningeal form and prion protein-CAA, respectively $[18,24,45,52,62]$. Interestingly, in some forms of CAA, glial activation and aggregated tau deposits are present, suggesting an important role for inflammation and tau accumulation in neurodegeneration associated with vascular amyloid deposition, as has been previously suggested for parenchymal amyloid accumulation $[8,57]$.

Noteworthy, several studies have suggested that pathologic changes of tau in neurons can impact
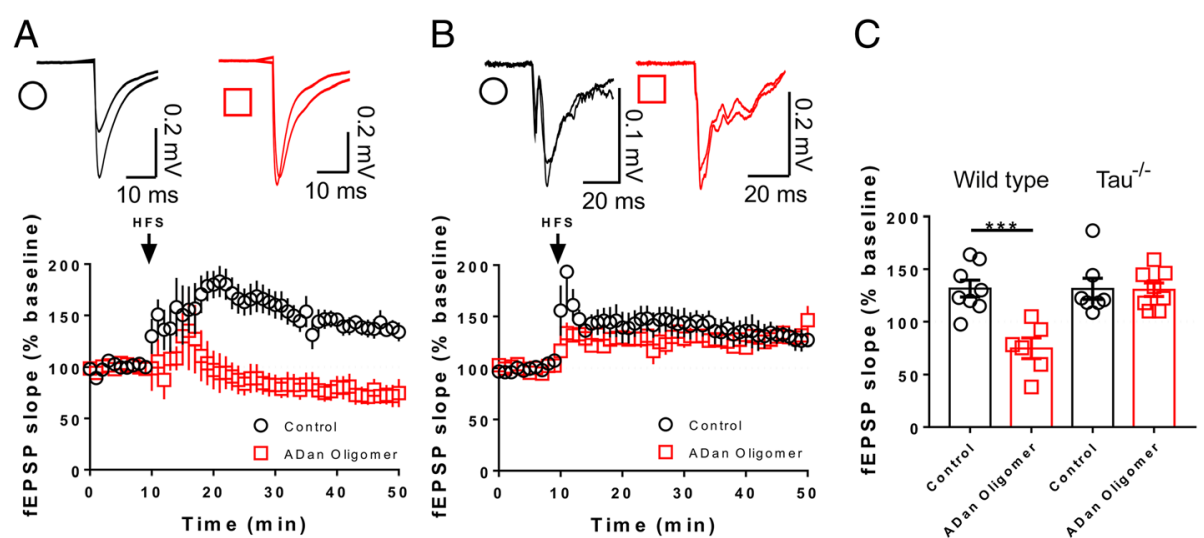

Fig. 8 ADan oligomers do not reduce LTP in slices of Tau ${ }^{-1-}$ mice. a ADan oligomers reduce LTP in slices of WT mice. Hippocampal Schaffer collateral-CA1 LTP in WT mice in control (circles) or after incubation with ADan oligomers (squares). Representative traces are the average baseline fEPSP (1-10 $\mathrm{min}$ ) and average fEPSP of the final $10 \mathrm{~min}$ of recording (40-50 min) for each condition. b Hippocampal Schaffer collateralCA1 LTP in Tau ${ }^{-/-}$mice in control (circles) or after incubation with ADan oligomers (squares). ADan oligomers do not reduce LTP in slices of $\mathrm{Tau}^{-1-}$ mice. The inset shows superimposed example traces before and $40 \mathrm{~min}$ after high-frequency stimulation for each condition. c Data show average of normalized fEPSP slope for final $10 \mathrm{~min}$ of recording (40-50 min) relative to $10 \mathrm{~min}$ baseline average. For $\mathrm{WT} ; p=0.0007, \mathrm{t}_{12}=4.537$, Unpaired Student's t test; $n=8$ slices Ctrl from 4 mice, $\mathrm{n}=6$ slices ADan oligomer ( $400 \mathrm{nM}$ ) from 4 mice. For Tau ${ }^{-1-} ; p=0.9440, \mathrm{t}_{13}=0.0716$, Unpaired Student's t test; $n=7$ slices Ctrl from 4 mice, $n=8$ slices ADan oligomer ( $400 \mathrm{nM}$ ) from 4 mice 
brain endothelial cell biology, altering the integrity of the brain's microvasculature $[5,47]$. For instance, it has been shown that vessel wall remodeling of leptomeningeal arteries is an early-onset, tau pathology-dependent process, which may potentially contribute to downstream CAA-dependent microvascular pathology in AD patients [47]. Even more, other studies have demonstrated an increase of $\mathrm{BBB}$ permeability and the accumulation of tau oligomers in the cerebral microvasculature of human patients with progressive supranuclear palsy (PSP) $[4,10]$, emphasizing the role of tau aggregates in the functional and structural integrity of the cerebral vasculature. In a similar fashion, tau-overexpressing mice develop changes to blood vessels including abnormal, spiraling morphologies; reduced blood vessel diameter; and increased overall blood vessel density in the cortex [5]. Also, in a different mouse model for tauopathies, BBB dysfunction emerges at the same time that perivascular tau emerges around major hippocampal blood vessels. However, when tau expression is suppressed, $\mathrm{BBB}$ integrity is preserved, suggesting that the $\mathrm{BBB}$ can be stabilized in a tauopathic brain by reducing tau levels [7]. Overall, these studies strongly suggest that in relation to vascular damage, tau aggregation is not a unidirectional event where vascular damage initiates a series of events that triggers tau aggregation, but is rather a vicious cycle where tau pathology enhances vascular damage.

In Tg-FDD mice, expression of the Danish mutant form of $\mathrm{BRI}_{2}$ driven by the moPrnp promoter is sufficient for the development of CAA, suggesting that neural cells are the source of the cerebrovascular amyloid and highlighting the vasculotropic nature of the ADan peptide [59]. In the present study, we confirmed the presence of a robust activation of micro and astroglia surrounding vascular ADan deposits in Tg-FDD mice. We biochemically demonstrated an increase of hyperphosphorylated forms of tau in the Tg-FDD. This increase was only observed in certain phospho-tau epitopes, but not others that have been associated to tau NFTs in $\mathrm{AD}$, suggesting that the process of tau hyperphosphorylation associated to CAA deposits could be different from the hyperphosphorylation of tau associated to parenchymal deposition of amyloid. We also showed the presence of tau oligomers in perivascular regions, in the vicinity of ADan amyloid deposits, as well as in areas throughout the cerebral cortex. Based on our observations, at least in the context of FDD, we proposed a dual-mechanism of action with vascular amyloid deposits resulting in tau hyperphosphorylation/aggregation and subsequent neurodegeneration:

1) Indirect mechanism is where $A D a n$ peptides secreted from neurons accumulate around vascular vessels. Subsequently, vascular amyloid accumulation triggers perivascular astrogliosis and astrocytic tau oligomerization. Interestingly, astrocytes play a key role in maintaining the BBB via astrocytic end feet directly opposed to vascular endothelial cells [50], and tau has been shown to accumulate in these end feet in tauopathies [36, 41], including perivascular astrocytic tau deposits in CAA patients [60]. These results suggest that vascular damage, due to amyloid accumulation, could induce an astrocytic response that triggers tau misfolding.

In addition to maintaining $\mathrm{BBB}$ integrity, astrocytes also modulate synaptic function by the secretion and uptake of neurotransmitters such as glutamate [32]. Considering this, plus a recent description of a frontotemporal dementia variant that displayed reduced glutamate transporter-1 staining in a subset of tau-bearing astrocytes [21], and also that the sole presence of tau in astrocytes in a mouse model for tauopathies produces a significant decrease in glutamate transport capacity [17]; we can speculate that the decrease in synaptic markers observed in the Tg-FDD mouse model could be due to astrocytic dysfunction triggered by tau oligomers. Nevertheless, considering novel studies where the role of glia in relation to tau spreading is described [2, 46], we cannot rule out the propagation of tau oligomers from the astrocytes to neurons as a source of synaptic function disturbance in the Tg-FDD model.

2) Direct mechanism is where ADan peptide, cleaved from transmembrane neuronal $\mathrm{BRI}_{2}$, forms amyloid oligomers and is internalized by neurons. These intraneuronal aggregates could directly induce the aggregation of endogenous tau by a cross-seeding event that subsequently promotes synaptic dysfunction. A similar mechanism has been suggested for $A \beta$ and alpha-synuclein, in which both amyloids interact with tau via an interface to co-aggregate into hybrid oligomers $[31,56]$. We cannot exclude the possibility that the intraneuronal ADan could co-aggregate with tau in the Tg-FDD due to the neuronal over-expression of mutant $\mathrm{BRI}_{2}$ rather than a CAA specific phenotype. Nevertheless, it has been previously reported that $A \beta_{40}$, an amyloid highly associated with $A \beta-C A A$, can also form intraneuronal inclusions [30], suggesting that CAA-associated amyloids could also contribute to neurodegeneration via the formation of neuronal aggregates.

Overall, both proposed mechanisms enhance the relevance of tau in the pathogenesis associated to CAA. This is highly relevant considering a novel patient-based 
study where it was shown that tau burden could play a pivotal role in cognitive impairment in patients with subcortical vascular cognitive impairment (SCVI), suggesting that tau could represent a common pathway for dementia triggered by both cerebrovascular and parenchymal amyloid pathologies [40].

Previous studies have shown how endogenous WT tau appears to be required for parenchymal $A \beta$-amyloid accumulation and ApoE4 to cause synaptic, network, and cognitive deficits in mouse models of AD [1, 53, 54]. Tau ablation has also been shown to attenuate motor abnormalities in a Huntington's disease (HD) mouse model [20] and prevent deficits in spatial learning and memory after repeated mild frontal impact in WT mice [13]. Even more, tau reduction has the ability to block epileptogenesis of diverse causes, including epileptic activity triggered by pharmacological blockade of $\mathrm{GABA}_{\mathrm{A}}$ channels $[19,54]$, genetic ablation of the voltage-gated potassium channel subunit Kv1.1 [33], depletion of ethanolamine kinase or of the $\mathrm{K}^{+}-\mathrm{Cl}^{-}$cotransporter [33], or depletion of the voltage-gated sodium channel subunit Nav1.1 [26]. The mechanisms underlying these beneficial effects of tau reduction remain to be determined [48]. As mentioned above, recent evidence suggest that tau could be involved in a common pathway for neurodegeneration triggered by cerebrovascular abnormalities and parenchymal amyloid pathologies [40]. Thus, our findings that demonstrated how ADan amyloid aggregates required endogenous tau expression to exert cell death; synaptic and LTP impairment lead us to suggest that partial tau reduction could be considered a feasible approach for the treatment of dementias associated with CAA, at least in the context of FDD.

\section{Conclusions}

Previous efforts in $\mathrm{AD}$ and $\mathrm{AD}$-related dementias have aimed to understand the connection between parenchymal amyloid, tau aggregation, and neurodegeneration, with the contribution of vascular amyloid pathology to tau aggregation and neurodegeneration remaining understudied. To the best of our knowledge, this is the first study aiming to understand, in detail, the connection between vascular amyloid deposition and tau pathology. Using a set of in vitro and in vivo approaches, we proposed the existence of two possible mechanisms of how ADan vascular amyloid may trigger tau misfolding. Even more, the fact that tau reduction was sufficient to prevent neuronal synaptotoxicity due to the presence of ADan oligomers, an amyloid highly associated to vascular deposits substantiates, at least in FDD, tau level modulation as an effective therapeutic target for neurodegeneration associated with CAA.

\section{Additional file}

\begin{abstract}
Additional file 1: Figure S1. Doxycycline-inducible cell line expressing human mutant P301L tau. Western blot of cell lysate probed with Tau-5 antibody confirming the expression of tau induced by Dox. Figure S2. BRI2 processing in Familial Danish Dementia. Processing of mutant BRI2 by pro-protein convertases (PCs) generates the 34 amino acid peptide (ADan) and a mature form of BRI2 (m-BRI2). Processing by ADAM10 in the ectodomain of BRI2 releases the BRICHOS domain and an N-terminal fragment. Disulfide bonded loops in the BRICHOS domain and in the carboxy-terminus of BRI2 are indicated. Figure S3. ADan oligomers and monomers are internalized in HEK cells. Orthogonal images of reconstructed three-dimensional views of ADan (red) and nucleus (blue) by confocal images of HEK tau-P301L cells. ADan oligomers are internalized and accumulated intracellularly (right image). In a lower degree than oligomers, ADan monomers are internalized into cells too (middle image). PBS treated cells were utilized as negative controls. Figure S4. CAA in a transgenic mouse model for FDD: Thio-S detection of leptomeningeal and cortical blood vessels in the cerebellum and cortex of Tg-FDD mice. Figure S5. Young Tg-FDD mice do not show changes in tau. (A) Western blot of brain from 3 months old WT and TgFDD mice. (B) Graph showing WB quantification of p-tau S396/S404. Figure S6. Tau oligomers in Tg-FDD mice. IF using the TOMA antibody (green) revealed the presence of tau oligomers in the hippocampus, cortex, and cerebellum of 18 months old Tg-FDD mice. MC1-positive staining was also observed in the hippocampus, cortex, and cerebellum of these mice. Tau-/- was utilized as control. Figure S7. Glial activation associated to CAA. (A-F) IF of ADan amyloid (red) and GFAP (green) in Tg-FDD (A-C) and WT (D-F). (G-L) IF of ADan amyloid (red) and Iba1 (green) in Tg-FDD (G-I) and WT (J-L). Scale bar 25 m. (DOCX 10546 kb)
\end{abstract}

\begin{abstract}
Abbreviations
ABri: British amyloid; AD: Alzheimer's disease; ADan: Danish amyloid; ADRD: Alzheimer's disease related dementias; BBB: Blood brain barrier; CAA: Cerebral amyloid angiopathy; DIV: Days in vitro; Dox: Doxycycline; FA: Formic acid; FBD: Familial British Dementia; FDD: Familial Danish Dementia; fEPSP: Field excitatory postsynaptic potential;

IHC: Immunohistochemistry; LTP: Long term potentiation; Mapt: Microtubule associated protein tau; NFTs: Neurofibrillary tangles; PSP: Progressive supranuclear palsy; RT: Room temperature; Thio-S: Thioflavine S; WB: Western blot
\end{abstract}

\section{Acknowledgments}

We thank Dr. Rakez Kayed (University of Texas Medical Branch) for providing T22 and TOMA antibodies. We also thank Dr. Peter Davies (Albert Einstein College of Medicine) for providing MC1 and PHF1 antibodies. This research was supported by a NIH/NINDS K22NS092688, a NIH/NIA 1R01AG059639, an AARGD-591887 and a Showalter Research Trust Grant to C.L-R; and to B. A the NIH/NIAAA AA023507.

\section{Funding}

This work was supported by the NIH/NINDS (grant number K22NS092688), the NIH/NIA (grant number 1R01AG059639) and the Alzheimer's association (grant number AARGD-591887).

\section{Availability of data and materials}

Not Applicable.

\section{Authors' contributions}

CAL-R, conceived and coordinated the study; PC, XT, and AP assisted in animal maintenance and breeding; YiY and $Y a Y$ performed cell culture experiments, oligomers formation, and immunocytochemistry. PC, YiY, and $\mathrm{XT}$ performed primary culture experiments; $\mathrm{AP}, \mathrm{AO}$, and $\mathrm{YiY}$ performed immunohistochemistry; HJG and YiY performed cloning; BA and BM performed and coordinated electrophysiology experiments; RV provided Tg-FDD mice and anti-ADan antibody; CAL-R, YiY, PC, BA, BM, and RV performed analyzed of data and drafted the images for publication; CAL-R, RV, and $\mathrm{AO}$ wrote the manuscript. All authors read and approved the final manuscript. 


\section{Ethics approval}

Mice were housed at the Indiana University School of Medicine (IUSM) animal care facility and were maintained according to USDA standards (12-h light/dark cycle, food and water ad libitum), in accordance with the Guide for the Care and Use of Laboratory Animals (National Institutes of Health, Bethesda, MD).

\section{Consent for publication}

Not Applicable.

\section{Competing interests}

The authors declare that they have no competing interests.

\section{Publisher's Note}

Springer Nature remains neutral with regard to jurisdictional claims in published maps and institutional affiliations.

\section{Author details}

${ }^{1}$ Stark Neurosciences Research Institute, Indiana University School of Medicine, Indianapolis, IN 46202, USA. ${ }^{2}$ Department of Anatomy \& Cell Biology, Indiana University School of Medicine, Indianapolis, IN 46202, USA. ${ }^{3}$ Department of Psychiatry, Indiana University School of Medicine, Indianapolis, IN 46202, USA. ${ }^{4}$ Department of Pathology and Laboratory Medicine, Indiana University School of Medicine, Indianapolis, IN 46202, USA. ${ }^{5}$ Indiana Alzheimer Disease Center, Indiana University School of Medicine, Indianapolis, IN 46202, USA. 'Department of Radiology \& Imaging Sciences, Indiana University School of Medicine, Indianapolis, IN 46202, USA. ${ }^{7}$ Department of Pharmacology \& Toxicology, Indiana University School of Medicine, Indianapolis, IN 46202, USA. ${ }^{8}$ Indiana University School of Medicine, The Stark Neurosciences Research Institute, Neurosciences Research Building 214G, 320 West 15th Street, Indianapolis, IN 46202, USA.

Received: 29 December 2018 Accepted: 17 February 2019

Published online: 26 February 2019

\section{References}

1. Andrews-Zwilling Y, Bien-Ly N, Xu Qet al. (2010) Apolipoprotein E4 causes age- and Tau-dependent impairment of GABAergic interneurons, leading to learning and memory deficits in mice. J Neurosci 30:13707-13717 https:// doi.org/10.1523/JNEUROSCI.4040-10.2010

2. Asai H, Ikezu S, Tsunoda Set al. (2015) Depletion of microglia and inhibition of exosome synthesis halt tau propagation. Nat Neurosci 18:1584-1593 https://doi.org/10.1038/nn.4132

3. Attems J (2005) Sporadic cerebral amyloid angiopathy: pathology, clinical implications, and possible pathomechanisms. Acta Neuropathol 110:345-359. https://doi.org/10.1007/s00401-005-1074-9

4. Bartels AL, Willemsen AT, Kortekaas ret al. (2008) decreased blood-brain barrier P-glycoprotein function in the progression of Parkinson's disease, PSP and MSA. J Neural Transm (Vienna) 115:1001-1009 https://doi.org/10. 1007/s00702-008-0030-y

5. Bennett RE, Robbins AB, Hu M et al (2018) Tau induces blood vessel abnormalities and angiogenesis-related gene expression in P301L transgenic mice and human Alzheimer's disease. Proc Natl Acad Sci U S A 115:E1289-E1298. https://doi.org/10.1073/pnas.1710329115

6. Biffi A, Greenberg SM (2011) Cerebral amyloid angiopathy: a systematic review. J Clin Neurol 7:1-9. https://doi.org/10.3988/jcn.2011.7.1.1

7. Blair LJ, Frauen HD, Zhang B et al (2015) Tau depletion prevents progressive blood-brain barrier damage in a mouse model of tauopathy. Acta Neuropathol Commun 3:8. https://doi.org/10.1186/s40478-015-0186-2

8. Bloom GS (2014) Amyloid-beta and tau: the trigger and bullet in Alzheimer disease pathogenesis. JAMA Neurol 71:505-508. https://doi.org/10.1001/ jamaneurol.2013.5847

9. Boulouis G, Charidimou A, Greenberg SM (2016) Sporadic Cerebral Amyloid Angiopathy: Pathophysiology, Neuroimaging Features, and Clinical Implications. Semin Neurol 36: 233-243. https://doi.org/10.1055/s-00361581993

10. Castillo-Carranza DL, Nilson AN, Van Skike CE et al (2017) Cerebral microvascular accumulation of tau oligomers in Alzheimer's disease and related Tauopathies. Aging Dis 8:257-266. https://doi.org/10.14336/AD. 2017.0112
11. Castillo-Carranza DL, Sengupta U, Guerrero-Munoz MJ et al (2014) Passive immunization with Tau oligomer monoclonal antibody reverses tauopathy phenotypes without affecting hyperphosphorylated neurofibrillary tangles. J Neurosci 34:4260-4272. https://doi.org/10.1523/JNEUROSCI.3192-13.2014

12. Charidimou A, Martinez-Ramirez S, Shoamanesh Aet al. (2015) Cerebral amyloid angiopathy with and without hemorrhage: evidence for different disease phenotypes. Neurology 84: 1206-1212. https://doi.org/10.1212/WNL. 0000000000001398

13. Cheng JS, Craft R, Yu GQ et al (2014) Tau reduction diminishes spatial learning and memory deficits after mild repetitive traumatic brain injury in mice. PLoS One 9:e115765. https://doi.org/10.1371/journal.pone.0115765

14. Cisternas P, Louveau A, Bueno SM, Kalergis AM, Boudin H, Riedel CA (2016) Gestational hypothyroxinemia affects glutamatergic synaptic protein distribution and neuronal plasticity through neuron-astrocyte interplay. Mol Neurobiol 53:7158-7169. https://doi.org/10.1007/s12035-015-9609-0

15. Citron M (2010) Alzheimer's disease: strategies for disease modification. Nat Rev Drug Discov 9: 387-398. https://doi.org/10.1038/nrd2896

16. Cohen TJ, Guo JL, Hurtado DE et al (2011) The acetylation of tau inhibits its function and promotes pathological tau aggregation. Nat Commun 2:252. https://doi.org/10.1038/ncomms 1255

17. Dabir DV, Robinson MB, Swanson E et al (2006) Impaired glutamate transport in a mouse model of tau pathology in astrocytes. J Neurosci 26: 644-654. https://doi.org/10.1523/JNEUROSCI.3861-05.2006

18. de la Chapelle A, Tolvanen R, Boysen Get al. (1992) Gelsolin-derived familial amyloidosis caused by asparagine or tyrosine substitution for aspartic acid at residue 187. Nat Genet 2:157-160 https://doi.org/10.1038/ng1092-157

19. DeVos SL, Goncharoff DK, Chen G et al (2013) Antisense reduction of tau in adult mice protects against seizures. J Neurosci 33:12887-12897. https://doi. org/10.1523/JNEUROSCI.2107-13.2013

20. Fernandez-Nogales M, Cabrera JR, Santos-Galindo M et al (2014) Huntington's disease is a four-repeat tauopathy with tau nuclear rods. Nat Med 20:881-885. https://doi.org/10.1038/nm.3617

21. Ferrer I, Legati A, Garcia-Monco JC et al (2015) Familial behavioral variant frontotemporal dementia associated with astrocyte-predominant tauopathy. J Neuropathol Exp Neurol 74:370-379. https://doi.org/10.1097/NEN. 0000000000000180

22. Garringer HJ, Murrell J, D'Adamio L, Ghetti B, Vidal R (2010) Modeling familial British and Danish dementia. Brain Struct Funct 214:235-244. https:// doi.org/10.1007/s00429-009-0221-9

23. Garringer HJ, Murrell J, Sammeta N, Gnezda A, Ghetti B, Vidal R (2013) Increased tau phosphorylation and tau truncation, and decreased synaptophysin levels in mutant BRI2/tau transgenic mice. PLoS One 8: e56426. https://doi.org/10.1371/journal.pone.0056426

24. Ghetti B, Piccardo P, Spillantini MG et al (1996) Vascular variant of prion protein cerebral amyloidosis with tau-positive neurofibrillary tangles: the phenotype of the stop codon 145 mutation in PRNP. Proc Natl Acad Sci U S A 93:744-748

25. Ghetti B, Tagliavini F, Masters CL et al (1989) Gerstmann-Straussler-Scheinker disease. II. Neurofibrillary tangles and plaques with PrP-amyloid coexist in an affected family. Neurology 39:1453-1461

26. Gheyara AL, Ponnusamy R, Djukic B et al (2014) Tau reduction prevents disease in a mouse model of Dravet syndrome. Ann Neurol 76:443-456. https://doi.org/10.1002/ana.24230

27. Giaccone G, Mangieri M, Capobianco ret al. (2008) Tauopathy in human and experimental variant Creutzfeldt-Jakob disease. Neurobiol aging 29:1864-1873. https://doi.org/10.1016/j.neurobiolaging.2007.04.026

28. Giaccone G, Tagliavini F, Verga let al. (1990) neurofibrillary tangles of the Indiana kindred of Gerstmann-Straussler-Scheinker disease share antigenic determinants with those of Alzheimer disease. Brain res 530: 325-329

29. Giacobini E, Gold G (2013) Alzheimer disease therapy--moving from amyloid-beta to tau. Nat Rev Neurol 9:677-686. https://doi.org/10.1038/ nrneurol.2013.223

30. Gouras GK, Tampellini D, Takahashi RH, Capetillo-Zarate E (2010) Intraneuronal beta-amyloid accumulation and synapse pathology in Alzheimer's disease. Acta Neuropathol 119:523-541. https://doi.org/10.1007/ s00401-010-0679-9

31. Guerrero-Munoz MJ, Castillo-Carranza DL, Krishnamurthy S et al (2014) Amyloid-beta oligomers as a template for secondary amyloidosis in Alzheimer's disease. Neurobiol Dis 71:14-23. https://doi.org/10.1016/j.nbd. 2014.08.008

32. Haydon PG (2001) GLIA: listening and talking to the synapse. Nat Rev Neurosci 2:185-193. https://doi.org/10.1038/35058528 
33. Holth JK, Bomben VC, Reed JG et al (2013) Tau loss attenuates neuronal network hyperexcitability in mouse and Drosophila genetic models of epilepsy. J Neurosci 33:1651-1659. https://doi.org/10.1523/JNEUROSCl.3191-12.2013

34. Holton JL, Lashley T, Ghiso J et al (2002) Familial Danish dementia: a novel form of cerebral amyloidosis associated with deposition of both amyloidDan and amyloid-beta. J Neuropathol Exp Neurol 61:254-267

35. Holton JL, Ghiso J, Lashley Tet al. (2001) regional distribution of amyloid-Bri deposition and its association with neurofibrillary degeneration in familial British dementia. Am J Pathol 158:515-526. https://doi.org/10.1016/S00029440(10)63993-4

36. Ikeda K, Akiyama H, Kondo Het al. (1995) Thorn-shaped astrocytes: possibly secondarily induced tau-positive glial fibrillary tangles. Acta Neuropathol 90: 620-625

37. Jicha GA, Bowser R, Kazam IG, Davies P (1997) Alz-50 and MC-1, a new monoclonal antibody raised to paired helical filaments, recognize conformational epitopes on recombinant tau. J Neurosci Res 48:128-132

38. Jin R, Yang G, Li G (2010) Inflammatory mechanisms in ischemic stroke: role of inflammatory cells. J Leukoc Biol 87:779-789. https://doi.org/10. 1189/jlb.1109766

39. Karch CM, Cruchaga C, Goate AM (2014) Alzheimer's disease genetics: from the bench to the clinic. Neuron 83:11-26. https://doi.org/10.1016/j.neuron. 2014.05.041

40. Kim HJ, Park S, Cho H et al (2018) Assessment of Extent and Role of Tau in Subcortical Vascular Cognitive Impairment Using 18F-AV1451 Positron Emission Tomography Imaging. JAMA Neurol. https://doi.org/10.1001/ jamaneurol.2018.0975

41. Komori T (1999) Tau-positive glial inclusions in progressive supranuclear palsy, corticobasal degeneration and Pick's disease. Brain Pathol 9:663-679

42. Kumar-Singh S (2009) Hereditary and sporadic forms of abetacerebrovascular amyloidosis and relevant transgenic mouse models. Int J Mol Sci 10:1872-1895. https://doi.org/10.3390/ijms10041872

43. Lasagna-Reeves CA, Castillo-Carranza DL, Sengupta U et al $(2012,1946)$ Identification of oligomers at early stages of tau aggregation in Alzheimer's disease. FASEB J 26:-1959. https://doi.org/10.1096/fj.11-199851

44. Lasagna-Reeves CA, Rousseaux MW, Guerrero-Munoz MJ et al (2015) A native interactor scaffolds and stabilizes toxic ATAXIN-1 oligomers in SCA1. Elife 4. https://doi.org/10.7554/eLife.07558

45. Levy E, Lopez-Otin C, Ghiso J, Geltner D, Frangione B (1989) Stroke in Icelandic patients with hereditary amyloid angiopathy is related to a mutation in the cystatin C gene, an inhibitor of cysteine proteases. J Exp Med 169:1771-1778

46. Maphis N, Xu G, Kokiko-Cochran ON et al (2015) Reactive microglia drive tau pathology and contribute to the spreading of pathological tau in the brain. Brain 138:1738-1755. https://doi.org/10.1093/brain/awv081

47. Merlini M, Wanner D, Nitsch RM (2016) Tau pathology-dependent remodelling of cerebral arteries precedes Alzheimer's disease-related microvascular cerebral amyloid angiopathy. Acta Neuropathol 131:737-752. https://doi.org/10.1007/s00401-016-1560-2

48. Morris M, Maeda S, Vossel K, Mucke L (2011) The many faces of tau. Neuron 70:410-426. https://doi.org/10.1016/j.neuron.2011.04.009

49. Oshima K, Uchikado H, Dickson DW (2008) Perivascular neuritic dystrophy associated with cerebral amyloid angiopathy in Alzheimer's disease. Int J Clin Exp Pathol 1:403-408

50. Ransom B, Behar T, Nedergaard M (2003) New roles for astrocytes (stars at last). Trends Neurosci 26:520-522. https://doi.org/10.1016/j.tins.2003.08.006

51. Rapoport M, Dawson HN, Binder LI, Vitek MP, Ferreira A (2002) Tau is essential to beta -amyloid-induced neurotoxicity. Proc Natl Acad Sci U S A 99: 6364-6369. https://doi.org/10.1073/pnas.092136199

52. Revesz T, Holton JL, Lashley T et al (2009) Genetics and molecular pathogenesis of sporadic and hereditary cerebral amyloid angiopathies. Acta Neuropathol 118:115-130. https://doi.org/10.1007/s00401-009-0501-8

53. Roberson ED, Halabisky B, Yoo JW et al (2011) Amyloid-beta/Fyn-induced synaptic, network, and cognitive impairments depend on tau levels in multiple mouse models of Alzheimer's disease. J Neurosci 31:700-711. https://doi.org/10.1523/JNEUROSCI.4152-10.2011

54. Roberson ED, Scearce-Levie K, Palop JJ et al (2007) Reducing endogenous tau ameliorates amyloid beta-induced deficits in an Alzheimer's disease mouse model. Science 316:750-754. https://doi.org/10.1126/science.1141736

55. Schindelin J, Arganda-Carreras I, Frise E et al (2012) Fiji: an open-source platform for biological-image analysis. Nat Methods 9:676-682. https://doi. org/10.1038/nmeth.2019
56. Sengupta U, Guerrero-Munoz MJ, Castillo-Carranza DL et al (2015) Pathological interface between oligomeric alpha-synuclein and tau in synucleinopathies. Biol Psychiatry 78:672-683. https://doi.org/10.1016/j. biopsych.2014.12.019

57. Serpente M, Bonsi R, Scarpini E, Galimberti D (2014) Innate immune system and inflammation in Alzheimer's disease: from pathogenesis to treatment. Neuroimmunomodulation 21:79-87 https://doi.org/10.1159/000356529

58. Sipe JD, Benson MD, Buxbaum JN et al (2012) Amyloid fibril protein nomenclature: 2012 recommendations from the Nomenclature Committee of the International Society of Amyloidosis. Amyloid 19:167-170. https://doi. org/10.3109/13506129.2012.734345

59. Vidal R, Barbeito AG, Miravalle L, Ghetti B (2009) Cerebral amyloid angiopathy and parenchymal amyloid deposition in transgenic mice expressing the Danish mutant form of human BRI2. Brain Pathol 19:58-68. https://doi.org/10.1111/j.1750-3639.2008.00164.x

60. Vidal R, Calero M, Piccardo P et al (2000) Senile dementia associated with amyloid beta protein angiopathy and tau perivascular pathology but not neuritic plaques in patients homozygous for the APOE-epsilon4 allele. Acta Neuropathol 100:1-12

61. Vidal R, Frangione B, Rostagno A et al (1999) A stop-codon mutation in the BRI gene associated with familial British dementia. Nature 399:776-781. https://doi.org/10.1038/21637

62. Vidal R, Garzuly F, Budka H et al (1996) Meningocerebrovascular amyloidosis associated with a novel transthyretin mis-sense mutation at codon 18 (TTRD 18G). Am J Pathol 148:361-366

63. Vidal R, Revesz T, Rostagno A et al (2000) A decamer duplication in the $3^{\prime}$ region of the $B R I$ gene originates an amyloid peptide that is associated with dementia in a Danish kindred. Proc Natl Acad Sci U S A 97:4920-4925. https://doi.org/10.1073/pnas.080076097

64. Viswanathan A, Greenberg SM (2011) Cerebral amyloid angiopathy in the elderly. Ann Neurol 70:871-880. https://doi.org/10.1002/ana.22516

65. Vossel KA, Zhang K, Brodbeck J et al (2010) Tau reduction prevents Abeta-induced defects in axonal transport. Science 330:198. https://doi. org/10.1126/science.1194653

66. Wojtas AM, Kang SS, Olley BM et al (2017) Loss of clusterin shifts amyloid deposition to the cerebrovasculature via disruption of perivascular drainage pathways. Proc Natl Acad Sci U S A 114:E6962-E6971. https://doi.org/10. 1073/pnas.1701137114
Ready to submit your research? Choose BMC and benefit from:
- fast, convenient online submission
- thorough peer review by experienced researchers in your field
- rapid publication on acceptance
- support for research data, including large and complex data types
- gold Open Access which fosters wider collaboration and increased citations
- maximum visibility for your research: over $100 \mathrm{M}$ website views per year
At BMC, research is always in progress.
Learn more biomedcentral.com/submissions 